\title{
Minimally invasive direct pars repair with cannulated screws and recombinant human bone morphogenetic protein: case series and review of the literature
}

\author{
George M. Ghobrial, MD, Kenneth M. Crandall, MD, Anthony Lau, MD, Seth K. Williams, MD, and \\ Allan D. Levi, MD, PhD \\ Department of Neurological Surgery and The Miami Project to Cure Paralysis, University of Miami Miller School of Medicine, \\ Miami, Florida
}

\begin{abstract}
OBJECTIVE The objective of this study was to describe the use of a minimally invasive surgical treatment of lumbar spondylolysis in athletes by a fluoroscopically guided direct pars screw placement with recombinant human bone morphogenetic protein-2 (rhBMP-2) and to report on clinical and radiographic outcomes.

METHODS A retrospective review was conducted of all patients treated surgically for lumbar spondylolysis via a minimally invasive direct pars repair with cannulated screws. Demographic information, clinical features of presentation, perioperative and intraoperative radiographic imaging, and postoperative data were collected. A 1-cm midline incision was performed for the placement of bilateral pars screws utilizing biplanar fluoroscopy, followed by placement of a fully threaded 4.0-mm-diameter titanium cannulated screw. A tubular table-mounted retractor was utilized for direct pars fracture visualization and debridement through a separate incision. The now-visualized pars fracture could then be decorticated, with care taken not to damage the titanium screw when using a high-speed drill. Local bone obtained from the curettage was then placed in the defect with $1.05 \mathrm{mg}$ rhBMP-2 divided equally between the bilateral pars defects.
\end{abstract}

RESULTS Nine patients were identified (mean age $17.7 \pm 3.42$ years, range 14-25 years; 6 male and 3 female). All patients had bilateral pars fractures of $L-4(n=4)$ or $L-5(n=5)$. The mean duration of preoperative symptoms was 17.22 \pm 13.2 months (range 9-48 months). The mean operative duration was $189 \pm 29$ minutes (range 151-228 minutes). The mean intraoperative blood loss was $17.5 \pm 10 \mathrm{ml}$ (range 10-30 ml). Radiographic follow-up was available in all cases; the mean length of time from surgery to the most recent imaging study was $30.8 \pm 23.3$ months (range 3-59 months). The mean hospital length of stay was $1.13 \pm 0.35$ days (range 1-2 days). There were no intraoperative complications.

CONCLUSIONS Lumbar spondylolysis treatment with a minimally invasive direct pars repair is a safe and technically feasible option that minimizes muscle and soft-tissue dissection, which may particularly benefit adolescent patients with a desire to return to a high level of physical activity.

https://thejns.org/doi/abs/10.3171/2017.5.FOCUS17153

KEY WORDS spondylolysis; athletes; minimally invasive; direct pars repair; adolescent

$\mathrm{W}$ HILE lumbar spondylolysis in the general adult population may reach as high as $5 \%-7 \%$ in select studies, $3,6,7,12,16,19,31,32,38,45,46,67$ the actual incidence of spondylolysis in pediatric patients presenting with axial low-back pain may approach 50\%.,36 Numerous prior studies have described the presentation and management of lumbar spondylolysis, most commonly present- ing at L-5 in up to $95 \%$ of cases and followed by L-4 in $5 \%-15 \%$. $12,36,37,56$ The vertebral segments of greatest lordosis and flexibility in the lumbar spine are the L4-5 and L5-S1 motion segments, where the points of greatest facet overhang occur and the greatest biomechanical forces are applied to the posterior elements. Moreover, the coronal orientation of the L5-S1 facet joints has been found to

ABBREVIATIONS AP = anteroposterior; rhBMP-2 = recombinant human bone morphogenetic protein-2.

SUBMITTED March 8, 2017. ACCEPTED May 10, 2017.

INCLUDE WHEN CITING DOI: 10.3171/2017.5.FOCUS17153. 
greatly impede horizontal translation, transmitting greater stresses at the pars interarticularis of L-5. ${ }^{33,66}$ Lumbar spondylolysis is highly prevalent in collegiate athletes involved in collision and endurance sports in which the transfer of energy through high-impact forces results in frequent lumbar hyperextension. . $^{24-26,47,48,65}$ Pain typically manifests as axial low-back pain but often is noted to have radiculopathic features exacerbated by hyperextension. ${ }^{58}$

Diagnosis is most commonly performed by oblique radiographs of the lumbar spine. However, many nondisplaced pars fractures may not be evident on plain radiographs, and CT has been the mainstay of fracture identification and preoperative planning (Fig. 1). The initial management of lumbar spondylolysis is nonsurgical, and treatment that includes bracing, activity modification, and targeted physical therapy most often leads to a good response. ${ }^{56}$ Early recognition of surgery as an option for repair of the pars defect was first described by Buck in 1970, who used open subperiosteal exposure and curettage of the pars defect and intralaminar stabilization across the fracture. Interestingly, due to the lack of image-guided techniques of modern spinal instrumentation, malpositioning of screws in the L4-5 rostral disc space and radiculopathy attributed to compression of the L-5 spinal nerve in the superior aspect of the L5-S1 neural foramen were encountered in $1(6.3 \%)$ of the 16 cases described. ${ }^{5}$

Extensive modifications to this technique have been subsequently reported, such as the incorporation of combinations of wires, ${ }^{52,53}$ intralaminar and cortical screws, ${ }^{52,53}$ and pedicle screw-hook constructs ${ }^{29}$ to achieve fracture stabilization. Arguably, the most clinically important modification has been the introduction of image guidance and muscle-sparing approaches. The use of minimally invasive techniques for the surgical management of spinal disorders has gained considerable popularity with the goal of decreasing hospital length of stay by lowering blood loss and limiting disabling perioperative pain., 2,30,41,49,54

Previously, we reported on successful direct pars repair in 3 patients. ${ }^{63}$ The authors present a clinical case series of the further use of percutaneous direct pars screw repair for lumbar spondylolysis with the use of a minimally invasive tubular approach for curettage and bone grafting of the fracture defect.

\section{Methods}

This study was approved by the University of Miami Miller School of Medicine institutional review board.

A single-surgeon database was searched for all cases in which patients were treated surgically for lumbar spondylolysis without spondylolisthesis via a minimally invasive approach. Summary demographic information, clinical features of presentation, perioperative and intraoperative radiographic imaging, data on postoperative narcotic consumption, and visual analog scale back pain scores were collected and analyzed.

\section{Operative Technique}

This technique has been previously described. ${ }^{63}$ The patient was positioned prone and secured to a radiolucent Jackson surgical table (OSI). Neurophysiological monitor-

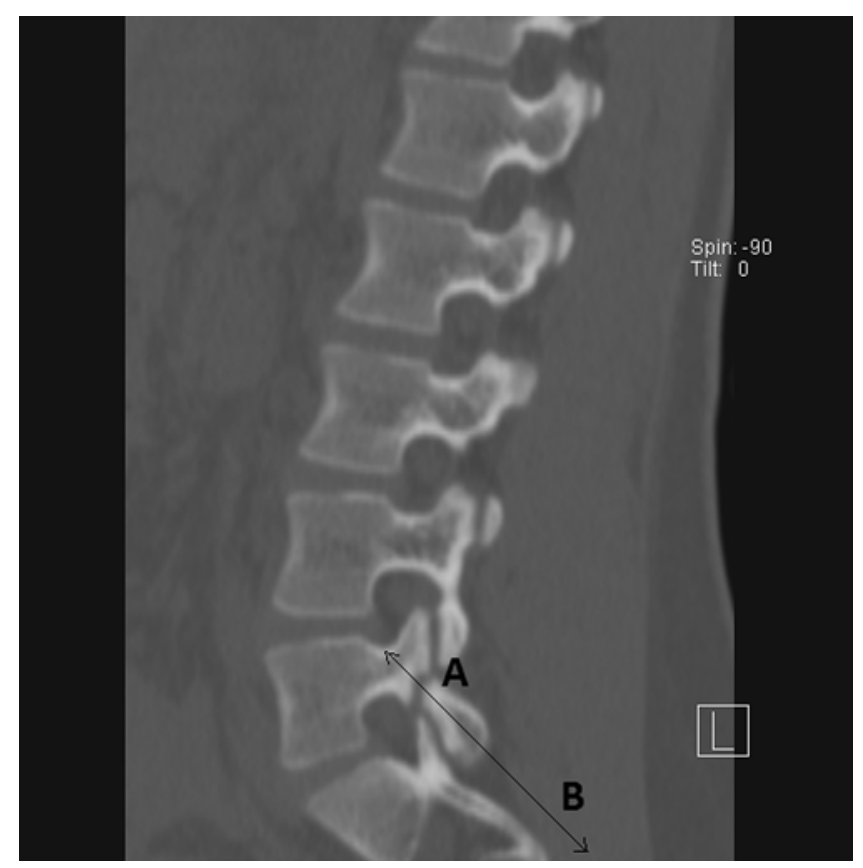

FIG. 1. Case 6. Chronic L-5 pars fracture. Sagittal CT reconstruction of the lumbar spine demonstrating chronic L-5 pars fracture. Increased density of the cortical margins of the L- 5 pars is indicative of a nonunion, as seen here. The ideal trajectory for planning a direct screw repair is perpendicular to this fracture site and through the long axis of the lamina (labeled A). The entry point and skin incision are then traced backward after an ideal screw trajectory is measured (labeled B).

ing was carried out with somatosensory and motor evoked potentials as well as continuous electromyography. The skin must be disinfected preoperatively all the way to the intergluteal fold. This is important because the trajectory can be very steep in certain patients requiring a caudal entry site. To achieve a single $1-\mathrm{cm}$ incision for the bilateral placement of pars screws, a midline incision is performed, with the precise rostral-caudal location determined with the use of biplanar fluoroscopy (Siemens). The location of the skin incision is identified by extending an imaginary line from the lamina to the skin on a lateral spine radiograph. The ideal trajectory under anteroposterior (AP) visualization forms a path entering the lateral inferior edge of the lamina and bisects the pedicle traversing the middle of the pars. The ideal trajectory has been recently described in one radiographic study of normal laminae in 100 volunteers by CT imaging of the lumbar spine by Menga et al. ${ }^{35}$

When the specific lateral trajectory is determined, the skin incision is made as well as a small fascial incision, followed by insertion of a Medtronic UCSS (Universal Cannulated Screw Set) guide along with the cannulated trocar, both of which are docked on the inferior entry point of the lamina. A 24-inch disposable threaded guidewire is secured to a drill and advanced through the cannulated trocar, into the lamina (Fig. 2), and across the pars fracture, ending in the pedicle (Fig. 3). With great care, the drill and drill bit are removed over the guidewire without moving the guidewire, and then the cannulated trocar is removed. An intraoperative CT scan is performed to confirm the desired location of the guidewire within the lamina (O-arm, Medtronic). A cannulated drill bit is now 


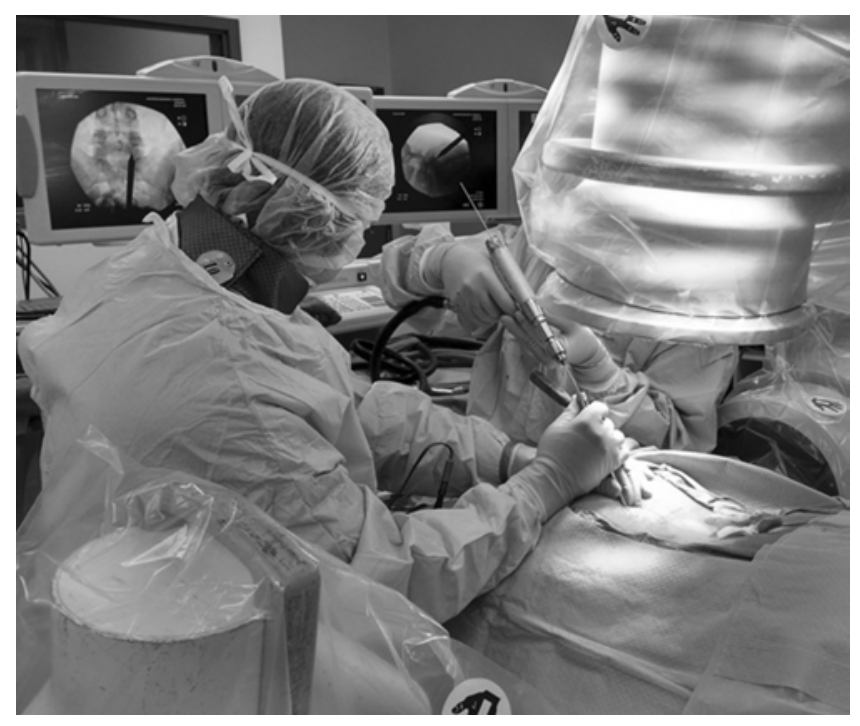

FIG. 2. Intraoperative docking of the UCSS guide and threaded guidewire advancement, as shown in an intraoperative photograph demonstrating the surgical setup and use of biplanar fluoroscopy. After incision, the UCSS guide and cannulated trocar are advanced through the fascia and docked on bone; this is followed by advancement of a threaded wire with a cannulated drill, as seen here. An ideal trajectory is achieved with a starting point beginning on the inferior bony edge of the lamina (visualized on screens in background).

advanced over the guidewire and the process repeated, followed by the cannulated tap. The guidewire can be measured with a provided cannulated depth gauge, or a second guidewire can be docked on the lamina, and the difference in height between the 2 guidewires at the proximal end can then be measured. A fully threaded 4.0-mm-diameter titanium cannulated lag screw is placed; lengths of 30-50 $\mathrm{mm}$ can be accommodated with this system (Fig. 4). Next, using lateral fluoroscopy, parasagittal incisions are made over the bilateral pars fractures. A METRx tubular tablemounted retractor (Medtronic) is placed using sequential dilators to a final working channel of $18 \mathrm{~mm}$. The now-visualized pars fracture can then be decorticated, with care taken to avoid damaging the titanium screw when using a high-speed drill. Local bone obtained from the curettage is then placed in the defect with $1.05 \mathrm{mg}$ of recombinant human bone morphogenetic protein-2 (rhBMP-2; Infuse, Medtronic) divided equally between the bilateral pars defects. The incisions are then closed in layers.

\section{Follow-Up}

Postoperative upright radiographs were obtained in all patients 6 weeks after surgery (Fig. 5). Confirmation of the final hardware positioning was performed intraoperatively with a fluoroscopic 3D reconstruction of the lumbar vertebrae of interest (using an $\mathrm{O}$-arm). Routine assessment of fusion and clinical follow-up was performed by the senior author (A.D.L.), and fusion was defined as the bridging of bone across the pars defect as interpreted on lumbar plain radiographs and CT imaging (Fig. 6).

\section{Results}

Nine patients were identified (mean age $[ \pm$ SD] $17.7 \pm$ 3.42 years, range $14-20$ years), 3 of whom were female $(33 \%)$. All patients presented with bilateral pars fractures at the L-4 $(n=4)$ or L-5 $(n=5)$ level (Table 1). The mean duration of preoperative symptoms was $17.22 \pm 13.2$ months (range 9-48 months). The mean operative duration was $189 \pm 29$ minutes (range 151-228 minutes). The mean intraoperative blood loss was $17.5 \pm 10 \mathrm{ml}$ (range $10-30 \mathrm{ml}$ ). Radiographic follow-up was performed in all 9 cases. The mean length of time from surgery to the most recent imaging study was $30.8 \pm 23.3$ months (range $3-59$ months). The mean length of hospital stay was $1.13 \pm 0.35$ days (range 1-2 days). The mean visual analog scale score for back pain improved from $7.33 \pm 2.35$ preoperatively to $0.11 \pm 0.33$ on the first postoperative examination (Table 2). Follow-up radiographs were available in all cases. Both
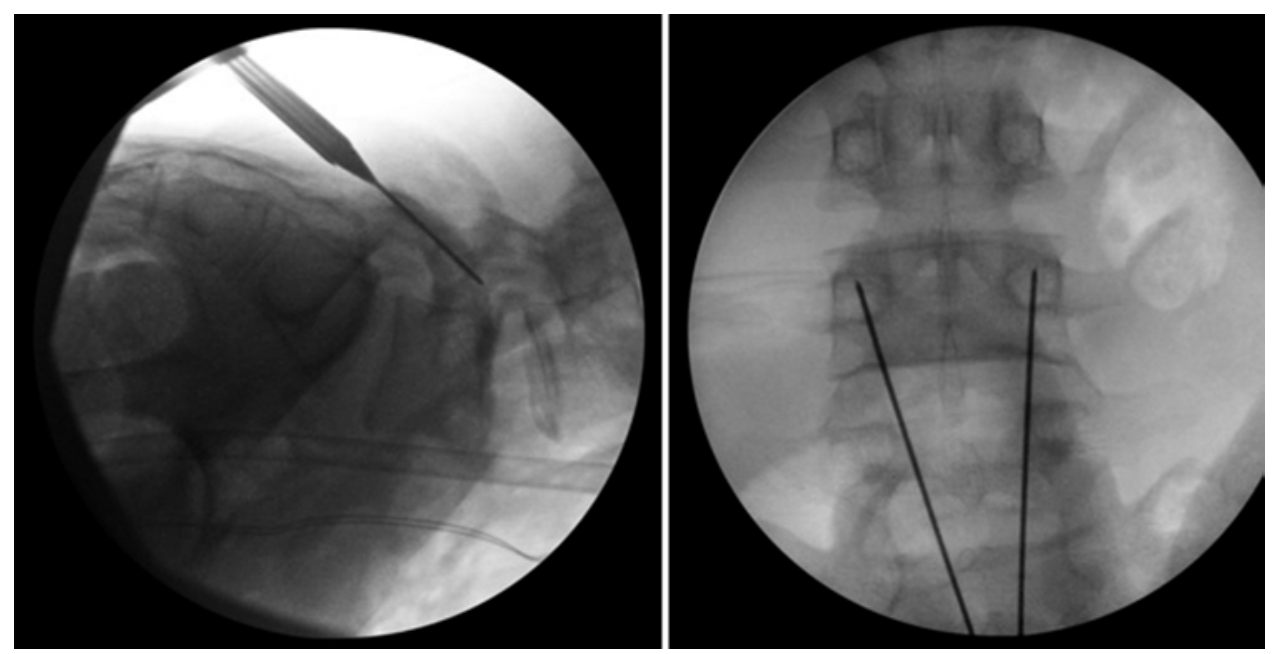

FIG. 3. Placement of bilateral L-5 intralaminar threaded guidewires. Intraoperative fluoroscopic views demonstrating bilateral placement of threaded guidewires in the lateral (left) and AP (right) projections. Note that on the AP projection the guidewires demonstrate lateral laminar entry and bisect the pedicle. On the lateral projection there is appropriate clearance of the L5-S1 neural foramen, and the rostral endplate or foramen is not violated. 


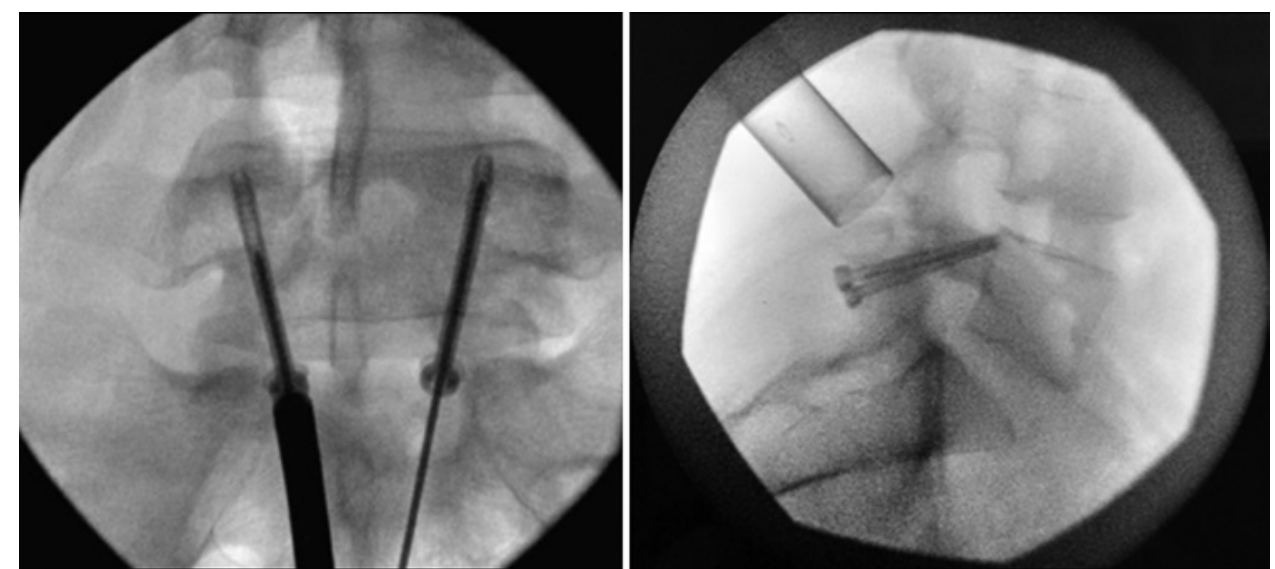

FIG. 4. Pars screw placement and fracture debridement. Intraoperative fluoroscopic views in the AP (left) and lateral (right) projection demonstrating bilateral placement of cannulated pars screws over threaded guidewires (left) and subsequent bilateral exposure of the pars fracture. Tubular-based retractors (right) allow for decortication.

CT and radiographic evidence of fusion were noted in all 6 patients with more than 1 year of follow-up (66.7\%). There were no intraoperative complications. In 1 case, the position of a threaded guidewire was considered to be too lateral within the lamina and fracture line under AP fluoroscopic visualization; a new trajectory was confirmed and a guidewire was placed in a satisfactory location. In that same patient, at 19 months' follow-up, despite complete relief of axial low-back pain, asymptomatic unilateral screw backout $(8 \mathrm{~mm})$ was noted on the right side.

\section{Discussion}

Due to the benign natural history of spondylolisthesis, ${ }^{3}$ patients with this condition should, in general, be treated with nonsurgical therapies and only considered for surgical treatment in the event of persistent or progressive symp-

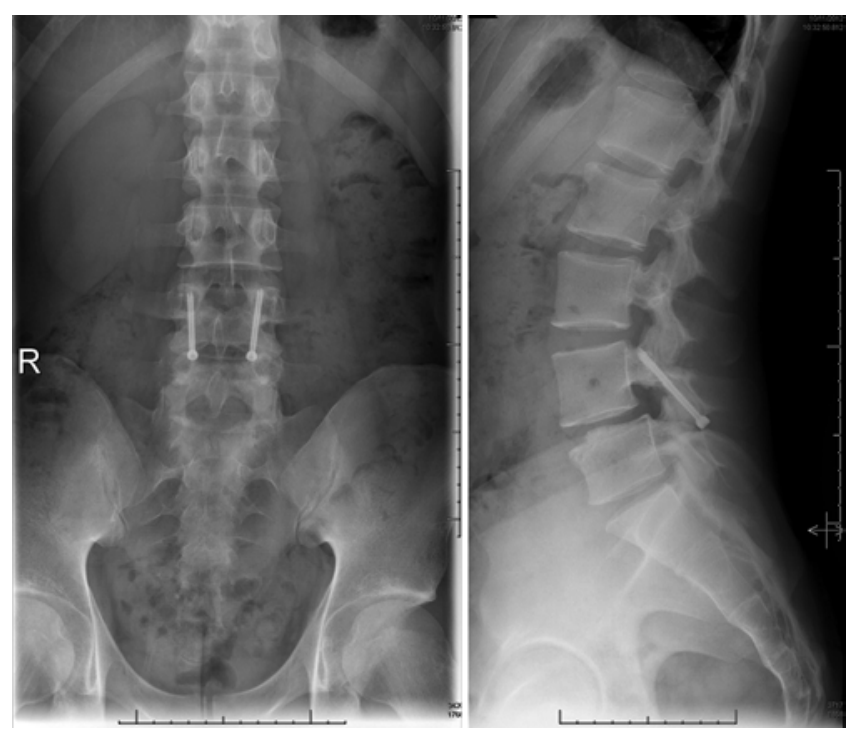

FIG. 5. Postoperative AP (left) and lateral (right) upright standing radiographs demonstrating bilateral placement of cannulated, fully threaded titanium cortical lag screws $4.0 \mathrm{~mm}$ in diameter and $46 \mathrm{~mm}$ long (UCSS). toms after all other options have been exhausted. However, it has been observed that physically active adolescents with a history of participation in competitive sports may develop nonunion. ${ }^{58}$ This was the case for $6(75 \%)$ of the 8 patients in our series who could recall the onset of their symptoms in correlation with competitive sporting activity (Table 1).

Numerous surgical options are available for the treatment of lumbar pars fractures. Among the earliest reported techniques and most similar to the surgical treatment in this series was that reported in 1970 by Buck, who described intralaminar screw placement across the lumbar pars fracture. ${ }^{5}$ This technique was developed out of the desire for a motion-sparing surgical treatment, as prior surgical treatments involved posterolateral arthrodesis with or without laminectomy or multilevel laminar wiring. ${ }^{23}$ Additionally, use of sublaminar wires, intralaminar screws, pedicle screws, and screw-hook constructs had been found to result in a moderate-to-high rate of pseudarthrosis. ${ }^{29}$ Surgical wiring, also referred to as Scott's wiring technique, involves wiring from the transverse process to the spinous process of the affected level and has been reported with varying degrees of success, due to the limited biomechanical fixation. ${ }^{1,28,39}$ Modifications to these aforementioned techniques have shown promise by providing incremental improvement in biomechanical strength, such as with wiring in combination with pedicle screw or hook placement. ${ }^{61}$ Moreover, compared with Scott's wiring technique and pedicle screw-cable constructs, the pedicle screw-hook construct had the highest degree of torsional and flexion/extension stiffness in a biomechanical study by Ulibarri et al. ${ }^{61}$ Deguchi and colleagues ${ }^{10}$ tested various constructs in a cadaveric biomechnical study, comparing Scott's and Buck's techniques, as well as a pedicle screw-wiring construct and a screw-rod-hook construct. The screw-rod-hook construct again was noted to have the greatest stiffness and the least motion across the pars defect. ${ }^{10}$ Interestingly, this finding goes against earlier biomechanial work by Crawford and colleagues, ${ }^{7}$ who found that greater stiffness and yield strength were achieved with Buck's technique than with the Morscher hook-screw construct and wiring technique. In the present series, we 

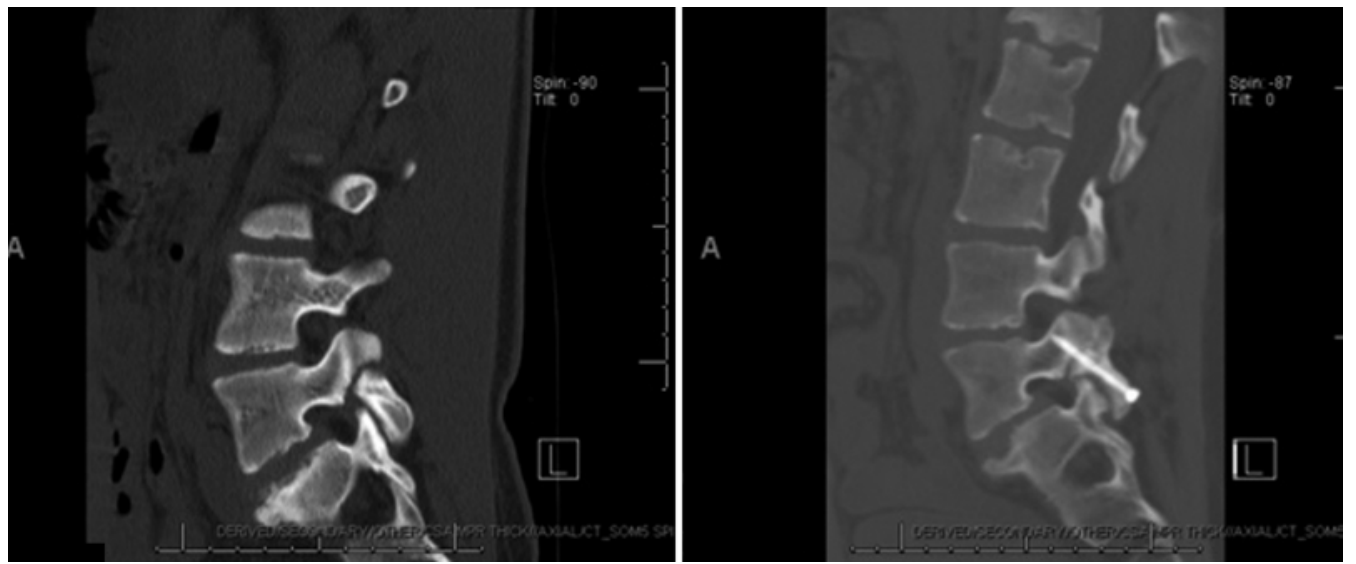

FIG. 6. Case 8. Chronic L-4 pars fracture in a 15-year-old girl. Sagittal CT reconstruction of the lumbar spine, demonstrating a chronic left L-4 pars fracture (left) treated with a cannulated screw placed across the fracture. Follow-up CT (right) obtained at 3 months demonstrating bridging fusion across the fracture diastasis.

used a fully threaded lag screw, fluoroscopic guidance, and placement of rhBMP-2 across the fracture site. In another report, Wilson et al. ${ }^{64}$ described the use of a threaded dynamic compression screw, which provides chronic compression on the fracture and bone graft. Similarly, Snyder et al. ${ }^{51}$ used a Buck screw technique with a dynamic compression screw system.

Other surgeons have adapted lumbar instrumentation techniques and applied them to pars fracture fixation. Most recently, Goldstein et al. ${ }^{14}$ reported the use of cortical screws and a spinous-process modular link in a minimally invasive fashion using intraoperative CT navigation. A midline incision was made, and pars screws were placed bilaterally under guidance with a standard inferomedial to superolateral trajectory, as previously described, with cortical screw fixation for spondylolisthesis. The cortical screw trajectory passed through the pars fracture and was able to fixate the fracture in this manner. A titanium rod was passed underneath the spinous process connecting the bilateral cortical screws, and the spinous process was compressed to the rod before final tightening. This compressed the fracture site before final tightening. Operating via a similar mechanism of fracture loading, Gillis et al..$^{13}$ used pedicle screws connected bilaterally with a polymer cord (Dynesys, Zimmer Biomet) passed beneath the spinous process in 4 competitive athletes. The advantage of this technique is a unified single incision and potentially shorter operative duration, as compared with the 3 incisions and multiple systems of UCSS and METRx tubular access. However, we feel that the extensive subperiosteal exposure contributes to significant pain at the operative site that would not be encountered otherwise, even with 3 incisions, as muscle-splitting approaches with an 18-mm tube preserve the muscle insertions. Another modification of an old technique involves the use of the translaminar screw from a contralateral percutaneous entry with intraoperative CT guidance. ${ }^{40}$ This is not much different from the starting approach with the translaminar facet screw initially popularized for the treatment of spondylolisthesis, ${ }_{15,22,34}$ with the exception that the trajectory limits placement of bilateral pars screws, greatly limiting the utility of their technique.

The safe use of intralaminar direct screw placement across the pars was reported by Buck, ${ }^{5}$ and then in 1988 by Pedersen et al. ${ }^{44}$ in 18 patients. It has been proposed by Kakiuchi ${ }^{29}$ as well as by Pederson and colleagues that the cause of the high pseudarthrosis rate (33\%) seen with intralaminar screw placement was hardware positioning.

TABLE 1. Summary of patient presentations

\begin{tabular}{ccclcc}
\hline $\begin{array}{c}\text { Case } \\
\text { No. }\end{array}$ & $\begin{array}{c}\text { Age }(\mathrm{yrs}), \\
\text { Sex }\end{array}$ & Level & \multicolumn{1}{c}{ Symptoms } & $\begin{array}{c}\text { Duration of } \\
\text { Symptoms (mos) }\end{array}$ & $\begin{array}{c}\text { Postop Radiographic } \\
\text { Surveillance (mos) }\end{array}$ \\
\hline 1 & $17, \mathrm{~F}$ & L-5 & Fall while playing field hockey, LBP & 12 & 54 \\
\hline 2 & $16, \mathrm{M}$ & L-4 & Collision while playing ice hockey, LBP & 12 & 59 \\
\hline 3 & $25, \mathrm{M}$ & L-4 & Left buttock \& gluteal pain & 12 & 50 \\
\hline 4 & $16, \mathrm{M}$ & L-5 & LBP & 48 & 24 \\
\hline 5 & $14, \mathrm{M}$ & L-5 & Progressive LBP related to competitive running & 12 & 8 \\
\hline 6 & $20, \mathrm{M}$ & L-5 & LBP related to lacrosse \& football & 30 & 12 \\
\hline 7 & $16, \mathrm{M}$ & L-4 & LBP attributed to football & 9 & 3 \\
\hline 8 & $15, \mathrm{~F}$ & L-4 & LBP related to track \& field & 8 & 54 \\
\hline 9 & $20, \mathrm{~F}$ & L-5 & LBP related to multiple sports & & 3 \\
\hline
\end{tabular}

LBP = low-back pain. 
TABLE 2. Clinical follow-up and inpatient narcotic usage

\begin{tabular}{ccccc}
\hline $\begin{array}{c}\text { Case } \\
\text { No. }\end{array}$ & \multicolumn{2}{c}{ VAS Score-Back Pain } & \multirow{2}{\text{LOS}}{$\begin{array}{c}\text { Inpatient Narcotic } \\
\text { (days) }\end{array}$} & $\begin{array}{cccc}\text { Postop } \\
\text { Usage (MED in mg) }\end{array}$ \\
\hline 1 & 9 & 1 & 1 & 217.5 \\
\hline 2 & 4 & 0 & 2 & 83.7 \\
\hline 3 & 10 & 0 & 1 & 22.5 \\
\hline 4 & 4 & 0 & 1 & 42.5 \\
\hline 5 & 5 & 0 & 1 & 5 \\
\hline 6 & 9 & 0 & 1 & 50 \\
\hline 7 & 8 & 0 & 1 & 21.5 \\
\hline 8 & 9 & 0 & 1 & 7.5 \\
\hline 9 & 8 & 0 & 1 & 60 \\
\hline \\
LOS = length of stay; MED $=$ morphine equivalent dosage; VAS = visual analog \\
scale. \\
* Most recent follow-up.
\end{tabular}

This is not surprising; as with the use of direct visualization alone, Buck described the technique as directed "... upward, forward, and slightly outward." ${ }^{5}$ In the present series, there were no instances of pseudarthrosis, with fusion demonstrated as early as 3 months postoperatively (Fig. 6). This high rate of fusion can be attributed to the patient population and technique: young patients, good bone quality, meticulous decortication at the fracture site, placement of a total of $1.05 \mathrm{mg}$ rhBMP-2, and compression loading of the fracture diastasis by lag screws. Recent series using laminar screw starting points have reported fusion rates ranging from $80 \%$ to $100 \%{ }^{8,9,18}$ This can be compared with $86 \%-100 \%$ using Scott's technique, $56 \%-$ $82 \%$ with the Morscher technique (a pedicle screw-hook construct introduced by Hefti and colleagues $\mathrm{s}^{20,21}$ ), and $83 \%$ with screw-rod-hook constructs. $4,11,17,18,20,21,27,39,42-44,55,59,60,62$ Hardcastle ${ }^{18}$ identified 23 patients who reported a preferred pitching-style in cricket termed "fast bowling," which is a technique requiring lumbar extension and thoracolumbar rotation, occurring approximately 600 times per week for 6 months a year. Of the 23 patients with low-back pain, $50 \%$ had a pars defect (5 unilateral and 5 bilateral) and 10 were successfully treated with direct pars screw repair and posterior iliac crest graft placement, leading to fusion in all 10 cases. In our series, only local bone obtained from the decortication was collected and placed at the fracture site. In Buck's series, posterior iliac crest was harvested and placed at the fracture site. ${ }^{5}$ However, the overall philosophy of this surgical approach is based on the minimization of tissue disruption, blood loss, pain, and length of hospital stay, and we found in our case series that the use of rhBMP-2 to avoid iliac crest bone graft harvesting was associated with a short hospital length of stay (mean 1.13 \pm 0.35 days), low blood loss $(17.5 \pm 10 \mathrm{ml})$, and very little if any opiate use. The use of rhBMP-2 in young patients should be accompanied by a thorough dialogue about the potential risk of cancer, radiculopathy, heterotopic bone formation, and elevated rates of surgical site infection. ${ }^{50}$

\section{Complications}

Numerous complications and a steep learning curve have been reported with the Buck technique. Reported complications include nerve injury, screw protrusion/ backout, screw malpositioning, screw loosening, pseudarthrosis, and iliac crest graft donor-site pain..$^{10,57,61}$ Overall, complication rates have been reported to be as high as $40 \%$ with the Buck technique, 14\% with Scott's wiring, and 44\% with Morscher's technique. . $^{4,5,11,27,43,44,60}$ The authors report no intraoperative complications in the present series. In 1 case, screw backout was noted in a patient in whom intraoperative repositioning of the threaded guidewire was required prior to drilling and tapping of the cortical bone. We confirm guidewire positioning prior to drilling and tapping laminar bone, as there is only one opportunity for adequate intraoperative fixation. Regardless, successful fusion occurred in all patients with follow-up, and no recurrent painful symptoms were noted.

\section{Conclusions}

Lumbar spondylolysis treatment with a minimally invasive direct pars repair is a safe and technically feasible option that minimizes muscle and soft tissue dissection. This may be of particular benefit in cases involving adolescents with a desire to return to a high level of physical activity.

\section{References}

1. Askar Z, Wardlaw D, Koti M: Scott wiring for direct repair of lumbar spondylolysis. Spine (Phila Pa 1976) 28:354-357, 2003

2. Bach K, Ahmadian A, Deukmedjian A, Uribe JS: Minimally invasive surgical techniques in adult degenerative spinal deformity: a systematic review. Clin Orthop Relat Res 472:1749-1761, 2014

3. Beutler WJ, Fredrickson BE, Murtland A, Sweeney CA, Grant WD, Baker D: The natural history of spondylolysis and spondylolisthesis: 45-year follow-up evaluation. Spine (Phila Pa 1976) 28:1027-1035, 2003

4. Bradford DS, Iza J: Repair of the defect in spondylolysis or minimal degrees of spondylolisthesis by segmental wire fixation and bone grafting. Spine (Phila Pa 1976) 10:673-679, 1985

5. Buck JE: Direct repair of the defect in spondylolisthesis. Preliminary report. J Bone Joint Surg Br 52:432-437, 1970

6. Cavalier R, Herman MJ, Cheung EV, Pizzutillo PD: Spondylolysis and spondylolisthesis in children and adolescents: I. Diagnosis, natural history, and nonsurgical management. J Am Acad Orthop Surg 14:417-424, 2006

7. Crawford CH III, Ledonio CG, Bess RS, Buchowski JM, Burton DC, Hu SS, et al: Current evidence regarding the etiology, prevalence, natural history, and prognosis of pediatric lumbar spondylolysis: a report from the scoliosis research society evidence-based medicine committee. Spine Deform 3:12-29, 2015

8. Debnath UK, Freeman BJ, Gregory P, de la Harpe D, Kerslake RW, Webb JK: Clinical outcome and return to sport after the surgical treatment of spondylolysis in young athletes. J Bone Joint Surg Br 85:244-249, 2003

9. Debnath UK, Freeman BJ, Grevitt MP, Sithole J, Scammell BE, Webb JK: Clinical outcome of symptomatic unilateral stress injuries of the lumbar pars interarticularis. Spine (Phila Pa 1976) 32:995-1000, 2007

10. Deguchi M, Rapoff AJ, Zdeblick TA: Biomechanical comparison of spondylolysis fixation techniques. Spine (Phila Pa 1976) 24:328-333, 1999

11. Dreyzin V, Esses SI: A comparative analysis of spondylolysis repair. Spine (Phila Pa 1976) 19:1909-1915, 1994

12. Fredrickson BE, Baker D, McHolick WJ, Yuan HA, Lubicky 
JP: The natural history of spondylolysis and spondylolisthesis. J Bone Joint Surg Am 66:699-707, 1984

13. Gillis CC, Eichholz K, Thoman WJ, Fessler RG: A minimally invasive approach to defects of the pars interarticularis: Restoring function in competitive athletes. Clin Neurol Neurosurg 139:29-34, 2015

14. Goldstein MJ, Bruffey J, Eastlack RK: New minimally invasive technique for direct pars interarticularis osteosynthesis using cortical screws and spinous-process modular link. Spine (Phila Pa 1976) 41:E1421-E1424, 2016

15. Grob D, Rubeli M, Scheier HJ, Dvorak J: Translaminar screw fixation of the lumbar spine. Int Orthop 16:223-226, 1992

16. Halvorsen TM, Nilsson S, Nakstad PH: [Stress fractures. Spondylolysis and spondylolisthesis of the lumbar vertebrae among young athletes with back pain.] Tidsskr Nor Laegeforen 116:1999-2001, 1996 (Norwegian)

17. Hambly M, Lee CK, Gutteling E, Zimmerman MC, Langrana $\mathrm{N}$, Pyun Y: Tension band wiring-bone grafting for spondylolysis and spondylolisthesis. A clinical and biomechanical study. Spine (Phila Pa 1976) 14:455-460, 1989

18. Hardcastle PH: Repair of spondylolysis in young fast bowlers. J Bone Joint Surg Br 75:398-402, 1993

19. Harvey J, Tanner S: Low back pain in young athletes. A practical approach. Sports Med 12:394-406, 1991

20. Hefti F: [Direct repair of spondylolysis with the hook screw.] Orthopade 26:769-773, 1997 (Ger)

21. Hefti F, Seelig W, Morscher E: Repair of lumbar spondylolysis with a hook-screw. Int Orthop 16:81-85, 1992

22. Heggeness MH, Esses SI: Translaminar facet joint screw fixation for lumbar and lumbosacral fusion. A clinical and biomechanical study. Spine (Phila Pa 1976) 16 (6 Suppl):S266-S269, 1991

23. Henderson ED: Results of the surgical treatment of spondylolisthesis. J Bone Joint Surg Am 48:619-642, 1966

24. Jackson DW: Low back pain in young athletes: evaluation of stress reaction and discogenic problems. Am J Sports Med 7:364-366, 1979

25. Jackson DW, Wiltse LL, Cirincoine RJ: Spondylolysis in the female gymnast. Clin Orthop Relat Res (117):68-73, 1976

26. Jackson DW, Wiltse LL, Dingeman RD, Hayes M: Stress reactions involving the pars interarticularis in young athletes. Am J Sports Med 9:304-312, 1981

27. Jeanneret B: Direct repair of spondylolysis. Acta Orthop Scand Suppl 251:111-115, 1993

28. Johnson GV, Thompson AG: The Scott wiring technique for direct repair of lumbar spondylolysis. J Bone Joint Surg Br 74:426-430, 1992

29. Kakiuchi M: Repair of the defect in spondylolysis. Durable fixation with pedicle screws and laminar hooks. J Bone Joint Surg Am 79:818-825, 1997

30. Koreckij T, Park DK, Fischgrund J: Minimally invasive spine surgery in the treatment of thoracolumbar and lumbar spine trauma. Neurosurg Focus 37(1):E11, 2014

31. Kujala UM, Kinnunen J, Helenius P, Orava S, Taavitsainen M, Karaharju E: Prolonged low-back pain in young athletes: a prospective case series study of findings and prognosis. Eur Spine J 8:480-484, 1999

32. Kujala UM, Salminen JJ, Taimela S, Oksanen A, Jaakkola L: Subject characteristics and low back pain in young athletes and nonathletes. Med Sci Sports Exerc 24:627-632, 1992

33. Leone A, Cianfoni A, Cerase A, Magarelli N, Bonomo L: Lumbar spondylolysis: a review. Skeletal Radiol 40:683700, 2011

34. Markwalder TM, Reulen HJ: Translaminar screw fixation in lumbar spine pathology. Technical note. Acta Neurochir (Wien) 99:58-60, 1989

35. Menga EN, Jain A, Kebaish KM, Zimmerman SL, Sponseller PD: Anatomic parameters: direct intralaminar screw repair of spondylolysis. Spine (Phila Pa 1976) 39:E153-E158, 2014
36. Micheli LJ, Wood R: Back pain in young athletes. Significant differences from adults in causes and patterns. Arch Pediatr Adolesc Med 149:15-18, 1995

37. Morita T, Ikata T, Katoh S, Miyake R: Lumbar spondylolysis in children and adolescents. J Bone Joint Surg Br 77:620625,1995

38. Nazarian S: Spondylolysis and spondylolytic spondylolisthesis. A review of current concepts on pathogenesis, natural history, clinical symptoms, imaging, and therapeutic management. Eur Spine J 1:62-83, 1992

39. Nicol RO, Scott JH: Lytic spondylolysis. Repair by wiring. Spine (Phila Pa 1976) 11:1027-1030, 1986

40. Nourbakhsh A, Preuss F, Hadeed M, Shimer A: Percutaneous direct repair of a pars defect using intraoperative computed tomography scan: a modification of the Buck technique. Spine (Phila Pa 1976) 42:E691-E694, 2017

41. Oh T, Scheer JK, Fakurnejad S, Dahdaleh NS, Smith ZA: Minimally invasive spinal surgery for the treatment of traumatic thoracolumbar burst fractures. J Clin Neurosci 22:42-47, 2015

42. Ohmori K, Suzuki K, Ishida Y: Translamino-pedicular screw fixation with bone grafting for symptomatic isthmic lumbar spondylolysis. Neurosurgery 30:379-384, 1992

43. Pavlovcic V: Surgical treatment of spondylolysis and spondylolisthesis with a hook screw. Int Orthop 18:6-9, 1994

44. Pedersen AK, Hagen R: Spondylolysis and spondylolisthesis. Treatment by internal fixation and bone-grafting of the defect. J Bone Joint Surg Am 70:15-24, 1988

45. Purcell L: Causes and prevention of low back pain in young athletes. Paediatr Child Health 14:533-538, 2009

46. Purcell L, Micheli L: Low back pain in young athletes. Sports Health 1:212-222, 2009

47. Rossi F: Spondylolysis, spondylolisthesis and sports. J Sports Med Phys Fitness 18:317-340, 1978

48. Rossi F, Dragoni S: Lumbar spondylolysis: occurrence in competitive athletes. Updated achievements in a series of 390 cases. J Sports Med Phys Fitness 30:450-452, 1990

49. Seldomridge JA, Phillips FM: Minimally invasive spine surgery. Am J Orthop 34:224-232, 2005

50. Singh K, Ahmadinia K, Park DK, Nandyala SV, MarquezLara A, Patel AA, et al: Complications of spinal fusion with utilization of bone morphogenetic protein: a systematic review of the literature. Spine (Phila Pa 1976) 39:91-101, 2014

51. Snyder LA, Shufflebarger H, O'Brien MF, Thind H, Theodore N, Kakarla UK: Spondylolysis outcomes in adolescents after direct screw repair of the pars interarticularis. J Neurosurg Spine 21:329-333, 2014

52. Songer M: Repair of the pars interarticularis defect with a cable-screw construct. Spine (Phila Pa 1976) 23:284, 1998

53. Songer MN, Rovin R: Repair of the pars interarticularis defect with a cable-screw construct. A preliminary report. Spine (Phila Pa 1976) 23:263-269, 1998

54. Spoor AB, Öner FC: Minimally invasive spine surgery in chronic low back pain patients. J Neurosurg Sci 57:203-218, 2013

55. Suh PB, Esses SI, Kostuik JP: Repair of pars interarticularis defect. The prognostic value of pars infiltration. Spine (Phila Pa 1976) 16 (8 Suppl):S445-S448, 1991

56. Sutton JH, Guin PD, Theiss SM: Acute lumbar spondylolysis in intercollegiate athletes. J Spinal Disord Tech 25:422425,2012

57. Sys J, Michielsen J, Bracke P, Martens M, Verstreken J: Nonoperative treatment of active spondylolysis in elite athletes with normal X-ray findings: literature review and results of conservative treatment. Eur Spine J 10:498-504, 2001

58. Tallarico RA, Madom IA, Palumbo MA: Spondylolysis and spondylolisthesis in the athlete. Sports Med Arthrosc Rev 16:32-38, 2008

59. Tokuhashi Y, Matsuzaki H: Repair of defects in spondyloly- 
sis by segmental pedicular screw hook fixation. A preliminary report. Spine (Phila Pa 1976) 21:2041-2045, 1996

60. Tonino A, van der Werf G: Direct repair of lumbar spondylolysis. 10-year follow-up of 12 previously reported cases. Acta Orthop Scand 65:91-93, 1994

61. Ulibarri JA, Anderson PA, Escarcega T, Mann D, Noonan $\mathrm{KJ}$ : Biomechanical and clinical evaluation of a novel technique for surgical repair of spondylolysis in adolescents. Spine (Phila Pa 1976) 31:2067-2072, 2006

62. van der Werf GJ, Tonino AJ, Zeegers WS: Direct repair of lumbar spondylolysis. Acta Orthop Scand 56:378-379, 1985

63. Widi GA, Williams SK, Levi AD: Minimally invasive direct repair of bilateral lumbar spine pars defects in athletes. Case Rep Med 2013:659078, 2013

64. Wilson L, Altaf F, Tyler P: Percutaneous pars interarticularis screw fixation: a technical note. Eur Spine J 25:1651-1654, 2016

65. Wiltse LL: The etiology of spondylolisthesis. J Bone Joint Surg Am 44-A:539-560, 1962

66. Wiltse LL, Widell EH Jr, Jackson DW: Fatigue fracture: the basic lesion is isthmic spondylolisthesis. J Bone Joint Surg Am 57:17-22, 1975
67. Winter RB: The natural history of spondylolysis and spondylolisthesis. J Bone Joint Surg Am 67:823, 1985

\section{Disclosures}

Dr. Levi reports receipt of grant support from Medtronic and the Department of Defense.

\section{Author Contributions}

Conception and design: Levi. Acquisition of data: Levi, Ghobrial, Lau. Analysis and interpretation of data: Levi, Ghobrial, Lau. Drafting the article: Levi, Ghobrial, Crandall, Williams. Critically revising the article: Levi. Reviewed submitted version of manuscript: Levi, Ghobrial. Approved the final version of the manuscript on behalf of all authors: Levi. Administrative/techni$\mathrm{cal} / \mathrm{material}$ support: Levi. Study supervision: Levi.

\section{Correspondence}

Allan D. Levi, Department of Neurological Surgery, University of Miami Miller School of Medicine, Lois Pope LIFE Center, 1095 NW 14th Terrace (D4-6), Miami, FL 33136. email: alevi@med. miami.edu. 